\title{
Synergisms in antioxidant and anti-hepatocellular carcinoma activities of artichoke, milk thistle, and borututu syrups
}

Carla Pereira $^{\mathrm{a}}$, Ricardo C. Calhelha ${ }^{\mathrm{a}, \mathrm{b}}$, Lillian Barros ${ }^{\mathrm{a}}$, Maria João R.P. Queiroz ${ }^{\mathrm{b}}$, Isabel C.F.R. Ferreira ${ }^{\mathrm{a}, *}$

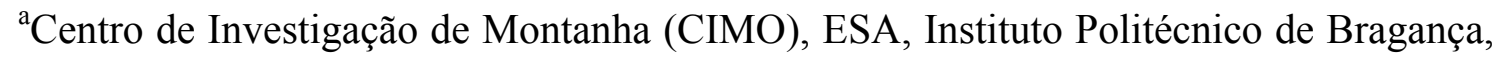
Campus de Santa Apolónia, apartado 1172, 5301-855 Bragança, Portugal

${ }^{\text {b} C e n t r o ~ d e ~ Q u i ́ m i c a, ~ U n i v e r s i d a d e ~ d o ~ M i n h o, ~ C a m p u s ~ d e ~ G u a l t a r ~ 4710-057 ~ B r a g a, ~}$ Portugal

* Author to whom correspondence should be addressed (e-mail: iferreira@ipb.pt telephone $+351-273-303219$; fax $+351-273-325405$ ). 


\begin{abstract}
Artichoke, borututu and milk thistle are three medicinal plants well-known for their capacity to prevent oxidative stress and many liver diseases. In a previous work, we reported the bioactivity of infusions and pills based on these plants; herein, the aim was to provide scientific information about the antioxidant and anti-hepatocellular carcinoma activities of syrups based on these medicinal plants and evaluate the synergism among the combined plants by using syrups based on the mixed plants or prepared form the combinations of individual species. The antioxidant activity was measured by radical scavenging activity, reducing power and lipid peroxidation inhibition, while the anti-hepatocellular carcinoma activity and the hepatotoxicity were evaluated using HepG2 human cell line and a primary culture of porcine liver cells, respectively. Milk thistle syrup proved to have the highest antioxidant activity in all the assayed methods, providing the best results either in single syrup or included in mixed syrups. Synergistic effects were the main interactions observed in the mixture of artichoke, borututu and milk thistle; mixing the syrups based on each single plant proved to be more efficient regarding antioxidant proposals than mixing plants in the same syrup. The latter was advantageous for anti-hepatocellular carcinoma activity.
\end{abstract}

Keywords: Medicinal plants; Syrups; Antioxidant activity; HepG2; Synergism 


\section{Introduction}

Medicinal plants are increasingly perceived as a source of biologically active compounds with beneficial effects in human health that may be included in the treatment of many diseases as new therapeutics or as foundations for the development of new drugs (Cragg and Newman, 2013). Nevertheless, their prevalent use and easy availability has raised concerns over their quality, efficacy and safety (Campos et al., 1089). Indeed, the chemical composition of these plants is not constant and the presence of chemicals that claims to have medicinal benefits (active principals) depends on a number of factors including the plant species, the time and season of harvest, the type of soil, the way the herb is prepared, etc. (Ferreres et al., 2013).

In order to contour the problem of standardization of the chemical composition of herbs and also due to the significant toxic effects in humans that the misidentification or the mislabeling can lead to, medicinal plants can be processed to become a dietary supplement that contains well-defined and constant composition (Bauer, 1998; Kunle et al., 2012; Liang et al., 2004).

Cynara scolymus L. (artichoke), Cochlospermum angolensis Welw. (borututu) and Silybum marianum (L.) Gaertn (milk thistle) are three medicinal plants well-known for their capacity to prevent oxidative stress and many liver diseases (Fehér et al., 1990; Campos et al., 1089; Ferreres et al., 2013; Adzet et al., 1987; Gebhardt, 1997). Several formulations based on the mentioned plants are available on market, such as infusions, pills, capsules and syrups, among others. The infusions and pills, which are the most commonly used, were previously assessed by our research group and proved to have antioxidant and anti-hepatocellular carcinoma activity (Pereira et al., 2013). Nevertheless, as far as we know, nothing has been reported on syrups. In fact, due to its 
high concentration, syrups based on those plants are also considered very useful formulations containing not only each species, but also different combinations of the three medicinal plants.

Nowadays, studies involving the evaluation of synergistic effects of combined plants are emerging and seem to highlight the potential of the mixtures when compared with the isolated plants (Almeida et al., 2011; Sidhu et al., 2009; Singha et al., 2011).

Thus, given the extensive use of artichoke, milk thistle and borututu as antioxidants and hepatoprotective, the present study aimed to provide scientific information about the bioactivity of syrups (antioxidant and anti-hepatocellular carcinoma activities) based on these medicinal plants. Furthermore, synergism among the combined in detriment to the isolated plants was also evaluated by using syrups based on the mixed plants or prepared form the combinations of individual species.

\section{Material and Methods}

\subsection{Samples and samples preparation}

Cynara scolymus L. (artichoke), Silybum marianum (L.) Gaertn (milk thistle) and Cochlospermum angolensis Welw. (borututu) were obtained from an herbalist shop in Bragança (Portugal) as syrups. According to the label information, artichoke syrup (AS) is a dietary supplement containing $100 \%$ of artichoke, water and preservative (methyl $p$ hydroxybenzoate); borututu syrup (BS) contains $10 \%$ of borututu roots, acidity regulator (citric acid), preservatives (potassium sorbate, sodium benzoate and propyl gallate) and sweeteners (aspartame, sodium cyclamate and saccharin); milk thistle syrup (MS) consists of $2.3 \%$ of milk thistle, sea buckthorn, carriers (fructose, water), sweetener (sorbitol), thickening agents (guar and locust bean gum), preservative 
(potassium sorbate), acidifying (L-ascorbic acid), stabilizer (pectin). Lastly, $(A+B+M) S$ is based on hydrophilic extracts of milk thistle (plant) $35 \%$, borututu (plant) $15 \%$, artichoke (plant) 15\%, and sweetener (sodium saccharin).

The concentration of the plant in the syrups was obtained from the recommended daily dose: AS at $1000 \mathrm{mg} / \mathrm{mL}, \mathrm{BS}$ at $100 \mathrm{mg} / \mathrm{mL}$ and $\mathrm{MS}$ at $26.4 \mathrm{mg} / \mathrm{mL}$. A syrup with the three plants (artichoke and borututu at $150 \mathrm{mg} / \mathrm{mL}$ and milk thistle at $350 \mathrm{mg} / \mathrm{mL}$; $(\mathrm{A}+\mathrm{B}+\mathrm{M}) \mathrm{S})$ was also obtained in the same shop. Lastly, a mixture with the syrups of each sample $(\mathrm{AS}+\mathrm{BS}+\mathrm{MS})$ was prepared at the same concentrations previously mentioned for the syrup with the three plants. According to the mentioned concentrations, the percentage of each plant in the mixture corresponds to $23 \%$ for artichoke, $23 \%$ for borututu and 54\% for milk thistle (these percentages were used for classification of synergistic and antagonist effects on the bioactive properties assayed). The five different syrups (AS, BS, MS, $(\mathrm{A}+\mathrm{B}+\mathrm{M}) \mathrm{S}$ and $\mathrm{AS}+\mathrm{BS}+\mathrm{MS}$; stock solutions) were successively diluted and submitted to an evaluation of antioxidant activity, antihepatocellular carcinoma activity and hepatotoxicity.

\subsection{Standards and reagents}

2,2-Diphenyl-1-picrylhydrazyl (DPPH) was obtained from Alfa Aesar (Ward Hill, USA). Gallic acid, catechin, trolox (6-hydroxy-2,5,7,8-tetramethylchroman-2carboxylic acid), ellipticine, phosphate buffered saline (PBS), acetic acid, sulforhodamine B (SRB), trichloroacetic acid (TCA) and Tris were purchased from Sigma (St. Louis, USA). Foetal bovine serum (FBS), L-glutamine, Hank's balanced salt solution (HBSS), trypsin-EDTA (ethylenediaminetetraacetic acid), nonessential amino acids solution $(2 \mathrm{mM})$, penicillin/streptomycin solution $(100 \mathrm{U} / \mathrm{mL}$ and $100 \mathrm{mg} / \mathrm{mL}$, respectively) and DMEM (Dulbecco's Modified Eagle Medium) were from Hyclone 
(Logan, USA). Water was treated in a Milli-Q water purification system (TGI Pure Water Systems, USA).

\subsection{Evaluation of antioxidant activity}

The antioxidant properties were evaluated by four different tests: DPPH radicalscavenging activity, reducing power, inhibition of $\beta$-carotene bleaching and inhibition of lipid peroxidation using TBARS (thiobarbituric acid reactive substances) in brain homogenates (Pereira et al., 2013). The results were expressed in $\mathrm{EC}_{50}$ values (sample concentration providing $50 \%$ of antioxidant activity or 0.5 of absorbance in the reducing power assay). Trolox was used as positive control.

2.3.1. DPPH radical-scavenging activity. This methodology was performed using an ELX800 microplate Reader (Bio-Tek Instruments, Inc; Winooski, USA). The reaction mixture on 96 well plate consisted in the sample solutions $(30 \mu \mathrm{L})$ and methanolic solution $(270 \mu \mathrm{L})$ containing DPPH radicals $\left(6 \times 10^{-5} \mathrm{~mol} / \mathrm{L}\right)$. The mixture was left to stand for $30 \mathrm{~min}$ in the dark, and the absorption was measured at $515 \mathrm{~nm}$. The radical scavenging activity (RSA) was calculated as a percentage of DPPH discoloration using the equation: $\% \mathrm{RSA}=\left[\left(\mathrm{A}_{\mathrm{DPPH}}-\mathrm{A}_{\mathrm{S}}\right) / \mathrm{A}_{\mathrm{DPPH}}\right] \times 100$, where $\mathrm{A}_{\mathrm{S}}$ is the absorbance of the solution containing the sample, and $\mathrm{A}_{\mathrm{DPPH}}$ is the absorbance of the DPPH solution.

2.3.2. Reducing power. The sample solutions $(0.5 \mathrm{~mL})$ were mixed with sodium phosphate buffer $(200 \mathrm{mmol} / \mathrm{L}, \mathrm{pH} 6.6,0.5 \mathrm{~mL})$ and potassium ferricyanide $(1 \% \mathrm{w} / \mathrm{v}$, $0.5 \mathrm{~mL})$. The mixture was incubated at $50{ }^{\circ} \mathrm{C}$ for $20 \mathrm{~min}$, and trichloroacetic acid $(10 \%$ w/v, $0.5 \mathrm{~mL})$ was added. The mixture $(0.8 \mathrm{~mL})$ was poured in the 48 wells plate, the 
same with deionised water $(0.8 \mathrm{~mL})$ and ferric chloride $(0.1 \% \mathrm{w} / \mathrm{v}, 0.16 \mathrm{~mL})$, and the absorbance was measured at $690 \mathrm{~nm}$ in the Microplate Reader mentioned above.

2.3.3. Inhibition of $\beta$-carotene bleaching. A solution of $\beta$-carotene was prepared by dissolving $\beta$-carotene $(2 \mathrm{mg})$ in chloroform $(10 \mathrm{~mL})$. Two milliliters of this solution were pipetted into a round-bottom flask. The chloroform was removed at $40{ }^{\circ} \mathrm{C}$ under vacuum and linoleic acid (40 mg), Tween 80 emulsifier (400 mg), and distilled water $(100 \mathrm{~mL})$ were added to the flask with vigorous shaking. Aliquots $(4.8 \mathrm{~mL})$ of this emulsion were transferred into test tubes containing sample solutions $(0.2 \mathrm{~mL})$. The tubes were shaken and incubated at $50{ }^{\circ} \mathrm{C}$ in a water bath. As soon as the emulsion was added to each tube, the zero time absorbance was measured at $470 \mathrm{~nm}$. $\beta$-Carotene bleaching inhibition was measured by the formula: $\beta$-carotene absorbance after 2h/initial absorbance) $\times 100$.

2.3.4. TBARS assay. Porcine (Sus scrofa) brains were obtained from official slaughtered animals, dissected, and homogenized with Polytron in an ice cold Tris-HCl buffer (20 $\mathrm{mM}, \mathrm{pH} 7.4$ ) to produce a $1: 2 \mathrm{w} / \mathrm{v}$ brain tissue homogenate which was centrifuged at $3000 \mathrm{~g}$ for $10 \mathrm{~min}$. An aliquot $(100 \mu \mathrm{L})$ of the supernatant was incubated with the sample solutions $(200 \mu \mathrm{L})$ in the presence of $\mathrm{FeSO}_{4}(10 \mathrm{mM} ; 100 \mu \mathrm{L})$ and ascorbic acid $(0.1$ $\mathrm{mM} ; 100 \mu \mathrm{L})$ at $37{ }^{\circ} \mathrm{C}$ for $1 \mathrm{~h}$. The reaction was stopped by the addition of trichloroacetic acid $(28 \% \mathrm{w} / \mathrm{v}, 500 \mu \mathrm{L})$, followed by thiobarbituric acid (TBA, $2 \%$, w/v, $380 \mu \mathrm{L}$ ), and the mixture was then heated at $80{ }^{\circ} \mathrm{C}$ for $20 \mathrm{~min}$. After centrifugation at $3000 \mathrm{~g}$ for $10 \mathrm{~min}$ to remove the precipitated protein, the color intensity of the malondialdehyde (MDA)-TBA complex in the supernatant was measured by its absorbance at $532 \mathrm{~nm}$. The inhibition ratio (\%) was calculated using the following 
formula: Inhibition ratio $(\%)=[(\mathrm{A}-\mathrm{B}) / \mathrm{A}] \times 100 \%$, where $\mathrm{A}$ and $\mathrm{B}$ were the absorbance of the control and the sample solution, respectively.

\subsection{Evaluation of hepatocellular carcinoma activity}

The anti-hepatocellular carcinoma activity was evaluated using HepG2, which is the most widely used tumour cell line and generally regarded as a good hepatocellular carcinoma model. HepG2 cells were routinely maintained as adherent cell cultures in DMEM supplemented with 10\% FBS, $2 \mathrm{mM}$ glutamine, $100 \mathrm{U} / \mathrm{mL}$ penicillin and 100 $\mathrm{mg} / \mathrm{mL}$ streptomycin, at $37^{\circ} \mathrm{C}$, in a humidified air incubator containing $5 \% \mathrm{CO}_{2}$. The cell line was plated at $1.0 \times 10^{4}$ cells/well in 96-well plates. Cells were then treated for $48 \mathrm{~h}$ with the sample solutions. Following this incubation period, the adherent cells were fixed by adding cold 10\% trichloroacetic acid (TCA, $100 \mu \mathrm{L}$ ) and incubated for $60 \mathrm{~min}$ at $4{ }^{\circ} \mathrm{C}$. Plates were then washed with deionized water and dried; sulforhodamine $\mathrm{B}$ solution $(0.1 \%$ in $1 \%$ acetic acid, $100 \mu \mathrm{L})$ was added to each plate well and incubated for $30 \mathrm{~min}$ at room temperature. Unbound SRB was removed by washing with $1 \%$ acetic acid. Plates were air dried, the bound SRB was solubilised with $10 \mathrm{mM}$ Tris $(200$ $\mu \mathrm{L}, \mathrm{pH} 7.4$ ) and the absorbance was measured at $540 \mathrm{~nm}$ (Pereira et al., 2013) in the microplate reader mentioned above. The results were expressed in $\mathrm{GI}_{50}$ values (sample concentration that inhibited $50 \%$ of the net cell growth). Ellipticine was used as positive control.

\subsection{Evaluation of hepatotoxicity}

The hepatotoxicity was accessed using a non-tumour liver primary culture established in our laboratory (PLP2). The cell culture was prepared from a freshly harvested porcine liver obtained from a local slaughter house. Once in the lab, the liver tissues were rinsed 
in Hank's balanced salt solution containing $100 \mathrm{U} / \mathrm{mL}$ penicillin, $100 \mu \mathrm{g} / \mathrm{mL}$ streptomycin and divided into $1 \times 1 \mathrm{~mm}^{3}$ explants. Five explants were placed in $25 \mathrm{~cm}^{2}$ tissue flasks in DMEM medium supplemented with 10\% FBS, 2 mM nonessential amino acids and $100 \mathrm{U} / \mathrm{mL}$ penicillin, $100 \mathrm{mg} / \mathrm{mL}$ streptomycin and incubated at $37^{\circ} \mathrm{C}$ with a humidified atmosphere containing $5 \% \mathrm{CO}_{2}$. The medium was changed every two days. Cultivation of the cells was continued with direct monitoring every two to three days using a phase contrast microscope. Before confluence, cells were subcultured and plated in 96-well plates at a density of $1.0 \times 10^{4}$ cells/well, and cultivated in DMEM medium with $10 \%$ FBS, $100 \mathrm{U} / \mathrm{mL}$ penicillin and $100 \mu \mathrm{g} / \mathrm{mL}$ streptomycin (Guimarães et al., 2013). Cells were treated for $48 \mathrm{~h}$ with the sample solutions and the same procedure described in the previous section for SRB assay was followed. The results were expressed in $\mathrm{GI}_{50}$ values (sample concentration that inhibited $50 \%$ of the net cell growth). Ellipticine was used as positive control.

\subsection{Classification of additive, synergistic or antagonistic effects}

Theoretical values for antioxidant activity of the mixtures were calculated as weighted mean experimental $\mathrm{EC}_{50}$ values (available in Table 1) and considering additive contributions of individual species in each percentage: $\mathrm{EC}_{50}=\mathrm{EC}_{50} \mathrm{AS} \times 0.23+$ $\mathrm{EC}_{50} \mathrm{BS} \times 0.23+\mathrm{EC}_{50} \mathrm{MS} \times 0.54$. The theoretical value for hepatocellular carcinoma activity is the $\mathrm{EC}_{50} \mathrm{MS}$ since $\mathrm{AS}$ and BS did not show activity.

The classification in additive (AD), synergistic (SN) or antagonistic (negative synergistic; AN) effects was performed as follow: AD: theoretical and experimental values reveal differences lower than 5\% (Burtis and Ashwood, 1999; Queirós et al., 2009); SN: experimental values are more than 5\% lower for $\mathrm{EC}_{50}$ when compared with 
theoretical values; $\mathrm{AN}$ : experimental values are more than $5 \%$ higher for $\mathrm{EC}_{50}$ when compared with theoretical values.

\subsection{Statistical analysis}

For all the experiments three samples $(n=3)$ were analysed and all the assays were carried out in triplicate. The results are expressed as mean values and standard deviation (SD). The differences between the different samples were analyzed using one-way analysis of variance (ANOVA) followed by Tukey's honestly significant difference post hoc test with $\alpha=0.05$, coupled with Welch's statistic. This treatment was carried out using SPSS v. 18.0 program.

\section{Results and Discussion}

Artichoke, borututu and milk thistle were assessed either as single plant syrup (AS, BS and MS, respectively), in different combinations of each plant in the same syrup $(\mathrm{AS}+\mathrm{BS}+\mathrm{MS})$ or in a mixture of different plant syrups $((\mathrm{A}+\mathrm{B}+\mathrm{M}) \mathrm{S})$. Free radicals scavenging activity, reducing power and lipid peroxidation inhibition were tested to evaluate the in vitro antioxidant properties of these syrups, HepG2 human cell line was used to assess anti-hepatocellular carcinoma activity, while a primary culture of porcine liver cells was established to evaluate hepatotoxicity. The results obtained for individual and combined syrups are shown in Tables $\mathbf{1}$ and $\mathbf{2}$, respectively.

MS was the most powerful sample in all the assays: DPPH scavenging activity $(0.32$ $\mathrm{mg} / \mathrm{mL})$, reducing power $(0.05 \mathrm{mg} / \mathrm{mL}), \beta$-carotene bleaching inhibition $(0.02 \mathrm{mg} / \mathrm{mL})$ and TBARS inhibition $(0.05 \mathrm{mg} / \mathrm{mL})$ followed by BS that also revealed high antioxidant activity $(0.15$ to $1.34 \mathrm{mg} / \mathrm{mL})$. Regarding the hepatocellular carcinoma activity, only MS revealed capacity to inhibit the proliferation of HepG2 cell line 
(280.48 $\mu \mathrm{g} / \mathrm{mL})$, despite none of the syrups revealed hepatotoxicity for normal liver cells (Table 1).

In a previous study (Pereira et al., 2013) with artichoke (A), borututu (B) and milk thistle (M) infusions and pills, B samples showed the highest antioxidant activity and the infusion also revealed anti-hepatocellular carcinoma activity $\left(\mathrm{GI}_{50}=146 \mu \mathrm{g} / \mathrm{mL}\right)$ without toxicity in non-tumor liver cells (PLP2), while A infusion showed capacity to inhibit the proliferation of HepG2 cell line $\left(\mathrm{GI}_{50}=52 \mu \mathrm{g} / \mathrm{mL}\right)$ but with toxicity for PLP2 cell culture $\left(\mathrm{GI}_{50}=72 \mu \mathrm{g} / \mathrm{mL}\right)$. Comparing infusions and pills with the syrups studied in the present work, the antioxidant activity varies as follows: infusion>pills $>$ syrup, infusion $>$ syrup $\approx$ pills and syrup $>$ infusion $>$ pills for $A, B$ and $M$, respectively.

Besides the syrups based on a single plant there are also available syrups mixing the three plants. Our research was guided by three main questions: 1) Are syrups based on mixed plants more bioactive than syrups with a single plant? 2) Have the syrups with mixed plants the same bioactivity of mixed plant syrups? 3) What are the main effects (synergistic, additive or antagonist) in the antioxidant and anti-hepatocellular carcinoma activity of the syrups containing the three plants?

MS proved to have the highest antioxidant activity in all the assayed methods, providing the best results among single syrup and even better than mixed syrups. The same tendency was observed for BS that gave higher antioxidant properties than mixed samples. Therefore, AS was the only sample which is favored by the mixture of plants in the same syrup $((\mathrm{A}+\mathrm{B}+\mathrm{M}) \mathrm{S})$ or by the mixture of syrups based on each plant (AS+BS+MS) (Table 2).

Mixing syrups, AS+BS+MS, allowed higher DPPH scavenging activity $(2.16 \mathrm{mg} / \mathrm{mL})$, reducing power $(0.78 \mathrm{mg} / \mathrm{mL})$ and TBARS inhibition $(0.25 \mathrm{mg} / \mathrm{mL})$ than the syrup with 
the three mixed plants, $(\mathrm{A}+\mathrm{B}+\mathrm{M}) \mathrm{S}$. Nevertheless, the latter gave higher $\beta$-carotene bleaching inhibition $(1.36 \mathrm{mg} / \mathrm{mL})$.

The experimental results of the antioxidant capacity of the mixtures were mostly better than the theoretical values (calculated with the results obtained from the individual syrups, Table 1) with the exception of $\beta$-carotene bleaching inhibition assay applied to AS+BS+MS (7.13 > $4.13 \mathrm{mg} / \mathrm{mL}$; Table 2). Thus, the synergistic effects (increase of antioxidant capacity) were predominant, being observed in $87.5 \%$ of the assays with only one experimental $\mathrm{EC}_{50}$ value giving antagonistic effect.

Regarding the hepatoprotective effect, only $(\mathrm{A}+\mathrm{B}+\mathrm{M}) \mathrm{S}$ revealed anti-hepatocellular carcinoma activity in HepG2 $(342.30 \mu \mathrm{g} / \mathrm{mL})$, but none of the syrups revealed hepatotoxicity in normal cells. Thus, an antagonistic effect of the three plants in $(\mathrm{A}+\mathrm{B}+\mathrm{M}) \mathrm{S}$ (decrease of anti-hepatocellular carcinoma activity) and in AS+BS+MS (no activity) in comparison to MS, was observed.

There are some studies involving combined natural matrices like different mushrooms, dietary supplements (plant pills or capsules) and even plant infusions and decoctions in order to achieve synergistic effects in the antioxidant activity. An experiment mixing different mushroom species (Boletus edulis, Calocybe gambosa, Cantharellus cibarius, Craterellus cornucopioides and Marasmius oreades) revealed that synergism was the most abundant effect in the antioxidant properties of the mixtures and that $M$. oreades was present in the best mixtures, while $C$. cibarius was present in the worst ones (Queirós et al., 2009). According to Vieira et al. (2012), reducing or scavenging properties require different proportions of mushrooms and the effect obtained after mixing different percentages depends on the used proportions. Regarding combinations of different dietary supplements (pills, capsules or bags with labeled antioxidant effects) performed by Almeida et al. (2011), the synergistic interaction was also the main 
observed effect. Similar results were obtained in a study involving plant (fennel, lemonverbena and spearmint) infusions and decoctions (Guimarães et al., 2011), concluding that these preparations are in fact more effective as mixtures than individually. Nevertheless, as far as we know, there are no studies involving syrups interaction that clarify their effect (synergistic, additive or antagonist) in the antioxidant and antihepatocellular carcinoma activity. The syrup of borututu is indicated to detoxify and purify the organism, to relieve liver disorders and is also known for its potential antiviral effect; artichoke syrup is used in cases of fluid retention or malfunction of the liver and gallbladder, and milk thistle syrup is applied in cases of poor digestion, fatty liver, jaundice, poisoning and biliary lithiasis (Longe, 2005). Due to their benefits, the three plants are also combined in syrups available in the market that claim to have beneficial effects in liver, stomach, spleen and the entire urinary tract diseases acting as detoxifiers and cleansers of the whole body, being very diuretic and efficient in removing grease and weight reduction (Longe, 2005). Thus, the combined syrup can be helpful in the treatment of health problems where the individual plants cannot act, and in those cases there are, indeed, synergistic effects.

Overall, MS proved to be the most potent syrup, giving support to the use of individual syrups for antioxidant and anti-hepatocellular carcinoma purposes; nevertheless, AS was highly favored when mixed with the other plants highlighting, in this case, the importance of syrups based on mixed plants. Synergistic effects were the main interactions observed in the mixture of artichoke, borututu and milk thistle; mixing the syrups based on each single plant proved to be more efficient regarding antioxidant proposals that mixing plants in the same syrup. The latter was advantageous for antihepatocellular carcinoma activity. Among the three studied plants, borututu infusion 
(Pereira et al., 2013) and milk thistle syrup (herein studied) gave the best results in the antioxidant activity with similar $\mathrm{EC}_{50}$ values of 0.02 to $0.32 \mathrm{mg} / \mathrm{mL}$ and 0.02 to 0.62 $\mathrm{mg} / \mathrm{mL}$, respectively, but regarding the capacity to inhibit the proliferation of HepG2 cell line, the infusion showed best results $\left(\mathrm{GI}_{50}=146 \mu \mathrm{g} / \mathrm{mL}\right)$ than the syrup $\left(\mathrm{GI}_{50}=280\right.$ $\mu \mathrm{g} / \mathrm{mL}$ ). Thus, to achieve the mentioned benefits of these plants, it seems unnecessary to acquire expensive syrups instead of the infusions, unless there are other benefits besides the herein reported, associated to the syrups.

\section{Acknowledgements}

The authors are grateful to the Foundation for Science and Technology (FCT, Portugal) for financial support to the research centre CIMO (PEst-OE/AGR/UI0690/2011) and L. Barros researcher contract under "Programa Compromisso com Ciência-2008.

\section{References}

Adzet T., Camarasa J., Laguna J.C. 1987. Hepatoprotective activity of polyphenolic compounds from Cynara Scolymus L. against $\mathrm{CCl}_{4}$ toxicity in isolated rat hepatocytes. J. Nat. Prod. 50, 612-617.

Almeida I.M.C., Barreira J.C.M., Oliveira M.B.P.P., Ferreira I.C.F.R. 2011. Dietary antioxidant supplements: Benefits of their combined use. Food Chem. Toxicol. $49,3232-3237$.

Bauer R. 1998. Quality criteria and standardization of phytopharmaceuticals: Can acceptable drug standards be achieved? Drug Inf. J. 32, 101-110.

Burtis C.A., Ashwood E.R. 1999. Tietz Textbook of Clinical Chemistry, Third Edition. 
Campos R., Garrido A., Guerra R., Valenzuela A. 1089. Silybin dihemisuccinate protects against glutathione depletion and lipid peroxidation induced by acetaminophen on rat liver. Planta Med. 55, 417-419.

Cragg G.M., Newman D.J. 2013. Natural products: A continuing source of novel drug leads. Biochim. Biophys. Acta 1830, 3670-3095.

Fehér J., Láng I., Nékám K., Gergely P., Mũzes G. 1990. In vivo effect of free radical scavenger hepatoprotective agents on superoxide dismutase (SOD) activity in patients. Tokai J. Exp. Clin. Med. 15, 129-134.

Ferreres, F., Grosso, C., Gil-Izquierdo, A., Valentão, P., Andrade, P. 2013. Ellagic acid and derivatives from Cochlospermum angolensis Welw. extracts: HPLC-DADESI/MSn profiling, quantification and in vitro anti-depressant, anticholinesterase and anti-oxidant activities. Phytochem. Anal. doi 10.1002/pca.2429.

Gebhardt R. 1997. Antioxidative and protective properties of extracts from leaves of the Artichoke (Cynara Scolymus L.) against hydroperoxide-induced oxidative stress in cultured rat hepatocytes. Toxicol. Appl. Pharmacol. 144, 279-286.

Guimarães R., Barros L., Carvalho A.M., Ferreira I.C.F.R. 2011. Infusions and decoctions of mixed herbs used in folk medicine: synergism in antioxidant potential. Phytother. Res. 25, 1209-1214.

Guimarães R., Barros L., Dueñas M., Calhelha R.C., Carvalho A.M., Santos-Buelga C., Queiroz M.J.R.P.Q., Ferreira I.C.F.R. 2013. Nutrients, phytochemicals and bioactivity of wild Roman chamomile: a comparison between the herb and its preparations. Food Chem. 136, 718-725. 
Kunle, Folashade O., Egharevba, Omoregie H., Ahmadu, Ochogu P. 2012. Standardization of herbal medicines - A review. Int. J. Biodiv. Conserv. 4, 101112.

Liang Y.Z., Xie P., Chan K. 2004. Quality control of herbal medicines. J. Chromatog. B, 812, 53-70.

Longe J.L. 2005. The Gale Encyclopedia of Alternative Medicine. 2nd Editio. Deirdre S. Blanchfield, Laurie Fundukian E, Watts, editors. Thomson GALE.

Pereira C., Calhelha R.C., Barros L., Ferreira I.C.F.R. 2013. Antioxidant properties, anti-hepatocellular carcinoma activity and hepatotoxicity of artichoke, milk thistle and borututu. Ind. Crop. Prod. 49, 61-65.

Queirós B., Barreira J.C.M., Sarmento A.C., Ferreira I.C.F.R. 2009. In search of synergistic effects in antioxidant capacity of combined edible mushrooms. Int. J. Food Sci. Nutr. 60, 160-172.

Sidhu O.P., Chandra H., Behl H.M. 2009. Occurrence of aflatoxins in mahua (Madhuca indica Gmel.) seeds: Synergistic effect of plant extracts on inhibition of Aspergillus flavus growth and aflatoxin production. Food Chem. Toxicol. 47, 774777.

Singha S., Banerjee S., Chandra G. 2011. Synergistic effect of Croton caudatus (fruits) and Tiliacora acuminate (flowers) extracts against filarial vector Culex quinquefasciatus. Asia Pacif. Trop. Biomed. S159-S164.

Vieira V., Mrques A., Barros L., Barreira J.C.M., Ferreira I.C.F.R. 2012. Insights in the antioxidant synergistic effects of combined edible mushrooms: phenolic and 
polysaccharidic extracts of Boletus edulis and Marasmius oreades. J. Food Nutr.

Res. 51, 109-116. 
Table 1. Antioxidant activity and hepatotoxicity of artichoke, borututu and milk thistle syrups (mean $\pm \mathrm{SD}$ ).

\begin{tabular}{|c|c|c|c|c|}
\hline & AS & BS & MS & $\begin{array}{l}\text { Positive } \\
\text { control }^{*}\end{array}$ \\
\hline \multicolumn{5}{|l|}{ Antioxidant activity $\left(\mathrm{EC}_{50}\right.$ values, $\left.\mathrm{mg} / \mathrm{mL}\right)$} \\
\hline DPPH scavenging activity & $225.27 \pm 9.76^{\mathrm{a}}$ & $1.34 \pm 0.06^{\mathrm{b}}$ & $0.32 \pm 0.01^{\mathrm{c}}$ & $0.04 \pm 0.00$ \\
\hline Reducing power & $73.15 \pm 0.19^{\mathrm{a}}$ & $1.06 \pm 0.00^{\mathrm{b}}$ & $0.05 \pm 0.00^{\mathrm{c}}$ & $0.03 \pm 0.00$ \\
\hline$\beta$-carotene bleaching inhibition & $17.38 \pm 0.38^{\mathrm{a}}$ & $0.51 \pm 0.04^{\mathrm{b}}$ & $0.02 \pm 0.00^{\mathrm{c}}$ & $0.003 \pm 0.00$ \\
\hline TBARS inhibition & $21.26 \pm 0.04^{\mathrm{a}}$ & $0.15 \pm 0.00^{\mathrm{b}}$ & $0.05 \pm 0.00^{\mathrm{c}}$ & $0.004 \pm 0.00$ \\
\hline \multicolumn{5}{|c|}{ Anti-hepatocellular carcinoma activity $\left(\mathrm{GI}_{50}\right.$ values, $\mu \mathrm{g} / \mathrm{mL}$ ) } \\
\hline HepG2 (hepatocellular carcinoma) & n.a. & n.a. & $280.48 \pm 18.14$ & $1.44 \pm 0.02$ \\
\hline \multicolumn{5}{|l|}{ Hepatotoxicity $\left(\mathrm{GI}_{50}\right.$ values, $\left.\mu \mathrm{g} / \mathrm{mL}\right)$} \\
\hline PLP2 (non-tumour liver primary culture) & n.a. & n.a. & n.a. & $2.14 \pm 0.01$ \\
\hline \multicolumn{5}{|c|}{$\begin{array}{l}\text { AS- artichoke syrup; BS- borututu syrup; MS- milk thistle syrup. } \\
{ }^{*} \text { Trolox and ellipticine for antioxidant and hepatotoxicity assays, respectively. } \mathrm{EC}_{50} \\
\text { values correspond to the sample concentration achieving } 50 \% \text { of antioxidant activity or } \\
0.5 \text { of absorbance in reducing power assay. } \mathrm{GI}_{50} \text { values correspond to the sample } \\
\text { concentration achieving } 50 \% \text { of growth inhibition in human tumour cell lines or in liver } \\
\text { primary culture PLP } 2 \text {. } \\
\text { n.a.- no activity up to } 400 \mu \mathrm{g} / \mathrm{mL} \text {. } \\
\text { In each row different letters mean significant differences between the } \mathrm{EC}_{50} \text { values }\end{array}$} \\
\hline
\end{tabular}


Table 2. Antioxidant activity and hepatotoxicity of syrups containing the three plants (artichoke, borututu and milk thistle) (mean $\pm \mathrm{SD})$.

$(\mathrm{A}+\mathrm{B}+\mathrm{M}) \mathrm{S} \quad \mathrm{AS}+\mathrm{BS}+\mathrm{MS}$

\begin{tabular}{|c|c|c|c|c|c|}
\hline & Theoretical & Experimental & Effect & Experimental & Effect \\
\hline \multicolumn{6}{|l|}{ Antioxidant activity $\left(\mathrm{EC}_{50}\right.$ values, $\left.\mathrm{mg} / \mathrm{mL}\right)$} \\
\hline DPPH scavenging activity & 52.29 & $5.77 \pm 0.02^{\mathrm{a}}$ & SN & $2.16 \pm 0.02^{\mathrm{b}}$ & SN \\
\hline Reducing power & 17.10 & $4.14 \pm 0.06^{\mathrm{a}}$ & SN & $0.78 \pm 0.01^{\mathrm{b}}$ & SN \\
\hline$\beta$-carotene bleaching inhibition & 4.13 & $1.36 \pm 0.02^{\mathrm{b}}$ & SN & $7.13 \pm 0.23^{\mathrm{a}}$ & AN \\
\hline TBARS inhibition & 4.95 & $0.60 \pm 0.02^{\mathrm{a}}$ & SN & $0.25 \pm 0.01^{\mathrm{b}}$ & SN \\
\hline \multicolumn{6}{|c|}{ Anti-hepatocellular carcinoma activity $\left(\mathrm{GI}_{50}\right.$ values, $\mu \mathrm{g} / \mathrm{mL}$ ) } \\
\hline HepG2 (hepatocellular carcinoma) & 280.48 & $342.30 \pm 27.39$ & AN & n.a. & AN \\
\hline \multicolumn{6}{|l|}{ Hepatotoxicity $\left(\mathrm{GI}_{50}\right.$ values, $\left.\mu \mathrm{g} / \mathrm{mL}\right)$} \\
\hline PLP2 (non-tumour liver primary culture) & n.a. & n.a. & - & n.a. & - \\
\hline
\end{tabular}

AD- additive effect; $\mathrm{SN}$ - synergistic effect; AN- antagonistic (negative synergistic) effect.

n.a.- no activity up to $400 \mu \mathrm{g} / \mathrm{mL}$.

Different letters in each row mean significant differences between the experimental $\mathrm{EC}_{50}$ values $(p<0.05)$. 